\title{
ACOMPAÑAMIENTO A UNA COMUNIDAD MOQUOIT EN EL DESARROLLO DE PROYECTOS PRODUCTIVOS AGROECOLÓGICOS
}

\section{Assessment to the Moqoit in the development of agroecological projects}

\author{
Mansilla, Natalia P.; Quiroz, Norma C.; Copetti, Guido \\ Dirección de Suelos y Agua Rural- Subsecretaría de Agricultura- Ministerio de Producción Industria y \\ Empleo del Chaco \\ E-mail: natalia.mansilla@hotmail.com
}

\begin{abstract}
RESUMEN
La Dirección de suelos y agua rural, data sus inicios desde los años 70, como organismo dentro del Ministerio de Producción- Provincia de Chaco. Se ha caracterizado por la intervención en el territorio, sobre todo con pequeños y medianos productores, focalizados en el trabajo a campo, desarrollo rural, sostenibilidad, cuidado de los suelos, prácticas adecuadas, género y ruralidad, entre otros. En esta publicación se presentará la experiencia en el acompañamiento brindado a una comunidad Moqoit. El objetivo del trabajo fue brindar asistencia técnica para el desarrollo de proyectos productivos agro-ecológicos a productores familiares y comunitarios, de la Moqoit de El Pastoril, Villa Ángela, Chaco. Se realizaron talleres teóricos-prácticos vinculados a la producción agroecológica, con tratamientos de recuperación de suelos, de características sódicas. Como resultados, se logró convertir un predio de 0,25 ha sin utilización, en una huerta comunitaria biodiversa, con recuperación de suelo. No es posible sostener los procesos, sin los actores locales que acompañan, monitorean y fortalecen estos procesos.
\end{abstract}

Palabras clave: vinculación, desarrollo productivo, conservación.

\begin{abstract}
The Rural Soil and Water Directorate dates back to the 1970s within Chaco Ministry of Production. This directorate has been working in action, with small and medium-size producers, focused on field work, rural development, sustainability, soil care, appropriate practices and gender and rurality among others. This publication will outline an experience carried out with the Moqoit. The aim of this work was to provide technical assistance to the development of agroecological productive projects carried out by family and community producers from the Moqoit in El Pastoril, Villa Ángela, Chaco. Theoreticalpractical workshops were held related to agroecological production about sodium soil recovery treatments. As a result, it was possible to turn 0.25 ha unused property into a biodiversity community garden with soil recovery. It is not possible to sustain the processes without the local supporters who go along, monitor and strengthen these processes.
\end{abstract}

Key words: linkage, productive development, conservation. 


\section{INTRODUCCIÓN}

La Dirección de Suelos y Agua Rural, data sus inicios desde los años 70, como organismo dependiente del Ministerio de Producción de la Provincia del Chaco. Se ha caracterizado por la intervención en el territorio, sobre todo con pequeños y medianos productores, focalizados en el trabajo a campo, desarrollo rural, sostenibilidad, cuidado de los suelos, prácticas adecuadas, género y ruralidad, entre otros. Su vinculación con asociaciones de productores, establecimientos educativos, docentes y comunidades aborígenes, ha marcado su trayectoria a lo largo de los años, en apoyo y fortalecimiento de las capacidades locales; así como el rescate del conocimiento tradicional, el desarrollo de destrezas y la reivindicación de procesos democráticos de participación local.

El éxodo y despoblamiento rural, y su contracara, el hacinamiento urbano, han llevado a la pérdida de la cultura tradicional, olvido y marginación social y cultural de gran parte de los espacios rurales. La Extensión rural es considerada como una herramienta para la inclusión social de pequeños productores, como instrumento de transformación de sus condiciones socioeconómicas, productivas y territoriales. La articulación interinstitucional se constituye como estrategia principal para fortalecer espacios y dinámicas asociativas e incrementar el agregado de valor a las producciones primarias, ya que los procesos necesarios para lograr los objetivos planteados son de carácter complejo y sistémico, cuyo éxito no puede garantizarse desde el abordaje individual ni por cada institución de manera aislada. Desde esa perspectiva, se ha trabajado en distintas iniciativas, a través de la articulación con distintos organismos sobre el territorio provincial.

Por otra parte, la agroecología es una disciplina científica, un conjunto de prácticas y un movimiento social. Como ciencia, estudia cómo los diferentes componentes del agro ecosistema interactúan. Como un conjunto de prácticas, busca afianzarse en sistemas agrícolas sostenibles que optimizan y estabilizan la producción. Como movimiento social, persigue papeles multifuncionales para la agricultura, promueve la justicia social, nutre la identidad y la cultura, y refuerza la viabilidad económica de las zonas rurales (Altieri, 1995).

En lugar de centrar su atención en algún componente particular del agroecosistema, la agroecología enfatiza las interrelaciones entre sus componentes y la dinámica compleja de los procesos ecológicos (Vandermeer, 1995). Para ello, apunta a una mirada más amplia, con un enfoque que tiene en cuenta los componentes del sistema, entendiendo las relaciones y procesos ecológicos, los agroecosistemas pueden ser manejados para mejorar la producción de forma más sustentable, con menores impactos negativos ambientales y sociales y un menor uso de insumos externos (Altieri, 1995).

Uno de los aspectos de la sustentabilidad de un agroecosistema es la calidad del suelo, la cual puede cambiar en forma natural, pero es siempre influenciada por el uso productivo (Franzluebbers, 2002). Cuándo se habla de calidad o salud de suelo se debe considerar su aptitud para producir sin que se pierda la capacidad del mismo de cumplir con sus funciones básicas, principalmente:

- Sostener su actividad, diversidad y productividad biológica;

- Regular y particionar agua y solutos;

- Cumplir la función de sostén para diferentes especies vegetales;

- Filtrar, taponar, inmovilizar, desintoxicar materiales orgánicos e inorgánicos (y los desechos);

- Almacenar y posibilitar el ciclo de nutrientes y

- Brindar apoyo a las estructuras socio- económicas

En esta publicación se presenta la experiencia de acompañamiento brindado a una comunidad Moqoit de El Pastoril, Villa Ángela (Chaco). Las comunidades Moqoit (Mocovíes) forman parte de los pueblos originarios del Gran Chaco Sudamericano. Habitantes tradicionales de los márgenes del río Bermejo. Durante el período colonial se fueron corriendo hacia el sur, llegando a Corrientes y Santa Fe. Estas comunidades campesinas indígenas, han sufrido en el tiempo distintas problemáticas vinculadas al acceso a la tierra, al agua, un proceso de sedentarización, el deterioro en la alimentación y la desvalorización de prácticas culturales ancestrales. El presente trabajo, desarrolló en el marco del Programa de Capacitaciones en el Sudoeste Chaqueño: "Producir alimentos sanos conservando la calidad ambiental en huertas familiares y comunitarias".

La soberanía alimentaria ha sido definida como el derecho de los pueblos a alimentos sanos, nutritivos y culturalmente adecuados, accesibles, producidos de forma sostenible y ecológica. Y, sobre todo, la defensa del derecho a decidir sus propios sistemas alimentarios y productivos (Rojas y Vallejos, 2018). 
El objetivo del trabajo fue brindar asistencia técnica para el desarrollo de proyectos productivos agroecológicos a productores, familiares y comunitarios, en la comunidad Moqoit de Pastoril, Villa Ángela Chaco.

\section{METODOLOGÍA Y RESULTADOS OBTENIDOS}

Se realizó un abordaje interinstitucional, entre el área de Proyectos de Comunidades Originarias, de la Subsecretaría de Agricultura, la Dirección de Suelos y Agua Rural, de la Subsecretaría de Recursos Naturales, ambas dependientes del Ministerio de Producción; la Unidad Regional del Sudoeste Chaqueño; y los establecimientos educativos Escuela Primaria N 418 Niño Mocoví; Secundaria $N^{\circ} 124$ Valentín Salteño y el Instituto Terciario CESBIM (Centro de Estudios Bilingüe Intercultural MOQOIT) del Ministerio de Educación, Ciencia y Tecnología (Chaco).

Al inicio del proceso, se hizo entrega de kits de herramientas, y materiales propios para el desarrollo de huertas comunitarias. Se planificaron los talleres, teniendo en cuenta, las características de la comunidad y los temas de interés de los mismos. Los talleres eran teóricos- prácticos, utilizando fotografías, y elementos didácticos; además de hacer preguntas a los asistentes a fin de favorecer la participación. La parte práctica, se realizó a campo, directamente sobre la huerta.

Los ejes desarrollados fueron:

- Sistemas productivos

- La huerta agroecológica. Organización.

- Siembra planificada de distintas especies. Características de las mismas.

- Cucurbitáceas.

- Suelos. Características. Tratamiento y recuperación de suelos salinos, a partir de desechos de la industria algodonera (residuo de desmotado de algodón).

- Reciclaje de residuos orgánicos.

- Características de las hortalizas. Importancia nutricional.

- Especies nativas silvestres, de uso medicinal y comestible.

- Valor de la autoproducción de alimentos.

Por otro lado, como uno de los ejes programados y observando las características en el predio, se tomaron muestras de suelos al inicio de la experiencia. Los datos del análisis preliminar, indicaron la existencia de un lote con bajo contenido de carbono y nitrógeno, buen contenido de fósforo, $\mathrm{pH}$ neutro, buenos contenidos de calcio, magnesio y potasio y alto contenido de sodio (Tabla 1).

A partir del diagnóstico realizado, se decidió hacer un tratamiento con residuo de desmotado, dada la facilidad de acceso y cercanía al Pastoril, mezclándolo con estiércol vacuno. En una superficie de $1500 \mathrm{~m}^{2}$ se aplicaron 150 kilos de residuo de desmotado con 50 kilos de estiércol. Se semi-incorporaron con la pala, entremezclando el suelo con los residuos aportados (Figuras 1y 2). A los tres meses de realizado el tratamiento, se realizó un nuevo análisis (Tabla 1).

Tabla 1. Resultados de los análisis de suelos al inicio de la experiencia y luego de 3 meses de haber aplicado el residuo de desmotado + estiércol. La profundidad de muestreo fue de $0-20 \mathrm{~cm}$.

\begin{tabular}{lcc}
\hline & Inicial & $\begin{array}{c}\text { Tres meses después } \\
\text { del } \\
\text { tratamiento }\end{array}$ \\
\hline Carbono (\%) & 0,60 & 1,50 \\
Nitrógeno t (\%) & 0,06 & 0,13 \\
Fósforo (ppm) & 64,54 & 42,50 \\
pH & 7,2 & 7 \\
Calcio & 10,20 & 8,50 \\
Magnesio & 4,40 & 3,20 \\
Potasio & 0,57 & 0,83 \\
Sodio & 5,80 & 1,22 \\
Conductividad & 3,34 & 2,00 \\
\hline
\end{tabular}


A partir del tratamiento con residuo de desmotado, se logró incrementar el carbono, nitrógeno y potasio; disminuir la conductividad eléctrica y el contenido de sodio (Tabla 1).
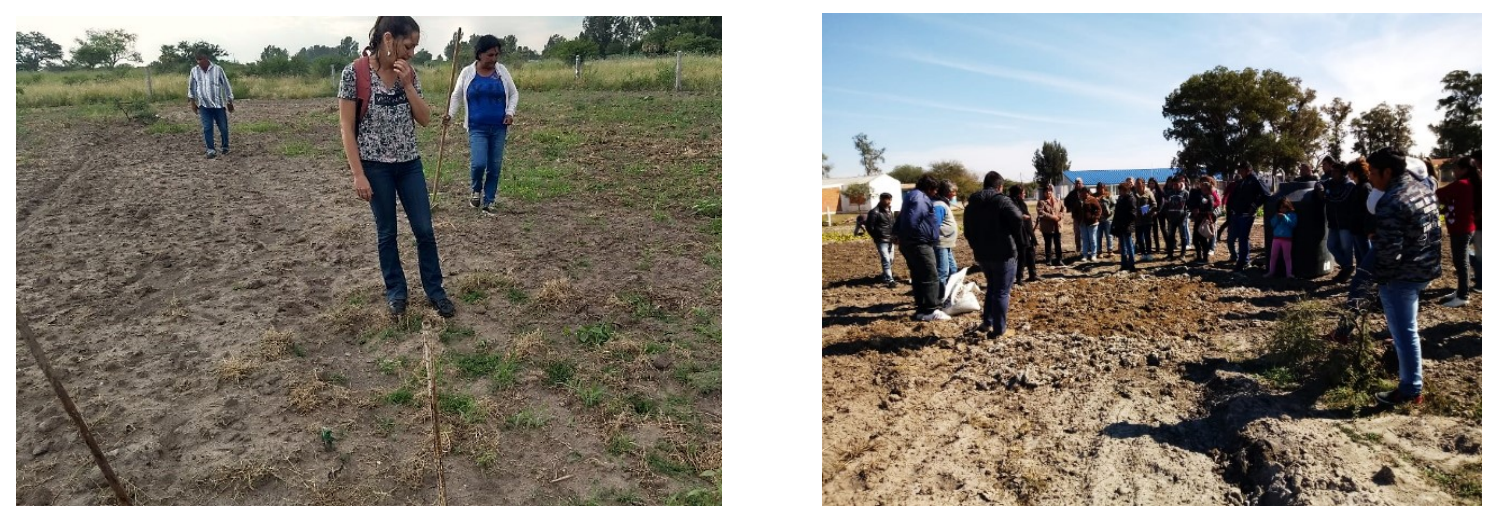

Figuras 1 y 2. Inicio de la actividad en el predio y tratamiento con residuo de desmotado y estiércol por los miembros de la comunidad.

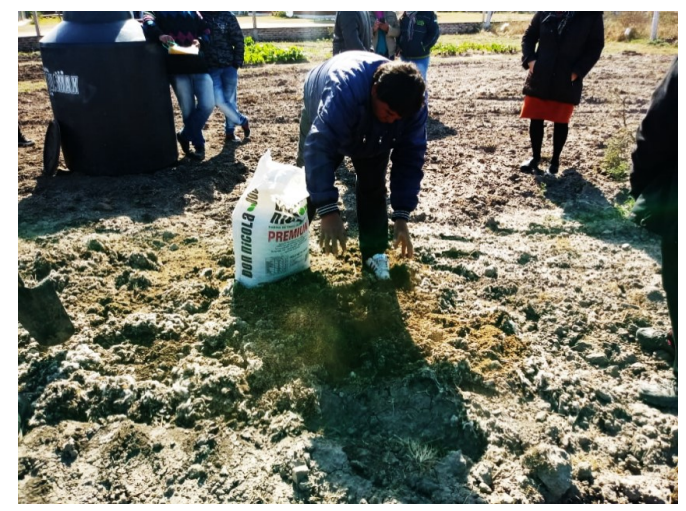

Figura 3. Aplicación del residuo de desmotado y estiércol al suelo.

El desarrollo de los talleres, permitió aportar ideas sobre hortalizas que comúnmente no son consumidas, así como trabajar sobre el rescate de saberes en especies utilizadas por la comunidad, para uso medicinal y comestible; trabajar con la planificación en la huerta, así como la importancia de la producción agroecológica y sus principios.

A partir del acompañamiento se logró convertir un predio de 0,25 ha sin utilización, en una huerta comunitaria biodiversa, donde horticultores comunitarios y alumnos vinculados a establecimientos educativos del Pastoril, trabajaron en forma organizada y planificada en las actividades propuestas (Figura 4).

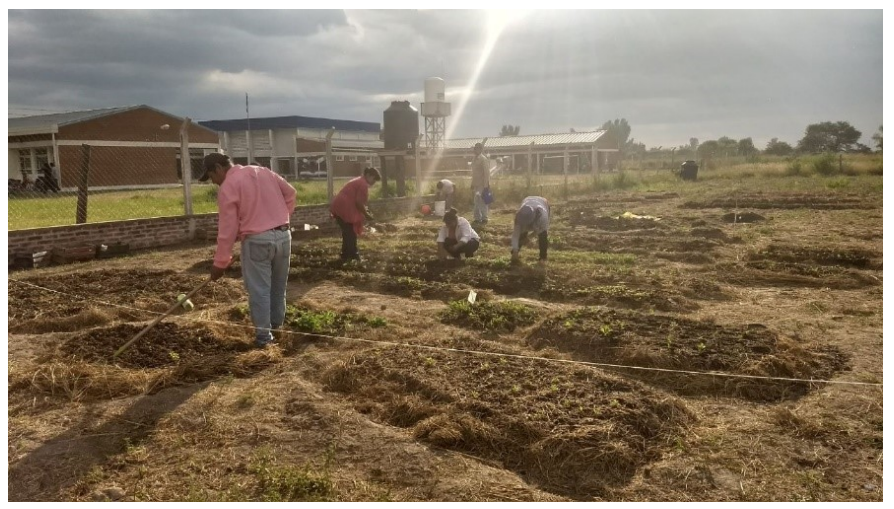

Figura 4. Grupo de la comunidad preparando los tablones de siembra.

El trabajo inter institucional propuesto, organizado y desarrollado, colaboró en la generación de «procesos», donde se ponen de manifiesto resultados, que benefician a las comunidades en el territorio. 
En un predio, con características no deseables productivamente, se pudo brindar alternativas de tratamiento de recuperación, a partir de desechos de la industria agropecuaria, reutilizando un recurso local y fácilmente disponible. Se logró un «Efecto multiplicador», dado que productores de los alrededores, docentes, técnicos agropecuarios y estudiantes de tecnicaturas en gestión agropecuaria, se sumaron al proceso. La capacidad de participar, no se logra inmediatamente, sino que se va adquiriendo paulatinamente en el proceso. Sobre todo, en la medida que se va respondiendo a las necesidades de la gente y a sus propios intereses, mostrando resultados concretos.

\section{CONSIDERACIONES FINALES}

La generación de procesos, requiere de un acompañamiento, que incluya responsabilidad frente a la tarea y el compromiso asumido. Solo esto, contribuye a la credibilidad, al entusiasmo y a los resultados. Los agroecosistemas pueden ser manipulados para mejorar la producción, con más sustentabilidad y con menos impactos ambientales y sociales negativos, a través de la recuperación y el uso de materiales locales, como también la organización y el acompañamiento a los actores en el territorio. La degradación de los suelos, dadas sus características naturales y/o por acciones antrópicas, puede ser modificada, con tratamientos acordes a la problemática diagnosticada.

Es necesario superar la visión reduccionista de la planificación de abordajes en los distintos estamentos, para el desarrollo de proyectos de corto plazo. Se necesita encaminar procesos cada vez más integrales y sostenibles en el tiempo y en del espacio.

Finalmente, no es posible sostener los procesos, sin los actores locales que acompañan, monitorean y fortalecen estos procesos. La inter institucionalidad, es primordial en el desarrollo.

\section{AGRADECIMIENTOS}

Al Licenciado Martín Garcilazo del área de proyectos de desarrollo productivo a pueblos originarios de la Subsecretaría de Agricultura del Ministerio de Producción y a Elina Torresgrosa de la Unidad Regional del Sudoeste Chaqueño que nos invitaron a ser parte del proceso.

\section{BIBLIOGRAFÍA}

Altieri, M. (1995). Agroecology: The science of sustainable agriculture. Westview Press.

Franzluebbers, A.J. (2002). Soil organic matter stratification ratio as an indicator of soil quality. Soil Till. Res. 66 (2): 95-106. https://doi.org/10.1016/S0167-1987(02)00018-1

Rojas, J. y Vallejos, L. (2018) Suelos sanos y agua segura para la soberanía alimentaria. https://inta.gob.ar/ documentos/suelos-sanos-y-agua-segura-para-la-soberania-alimentaria

Vandermeer, J. y Perfecto, I. (1995). Breakfast of biodiversity: the truth about rainforest destruction. Food First Books, Oakland. 185 pp.

Vandermeer, J. (1995). The ecological basis of alternative agriculture. Ann. Rev. Ecol. Syst. 26:201-224. 